\title{
UMA PALHA NA CIDADE
}

\author{
A straw in the city
}

\section{Irenísia Torres de Oliveira*}

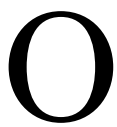

romance Recordações do escrivão Isaías Caminha, de Lima Barreto, é dos primeiros na literatura brasileira a mostrar conflitos do indivíduo diretamente relacionados à vida urbana. O rapaz pobre, vindo do interior, sem família ou amigos, abandonado pelo protetor a quem se devia recomendar, restringido nas possibilidades de estudo e trabalho pelo preconceito, cai na dinâmica da cidade sem atenuações. Na imagem do próprio romance, o estudante mulato e humilde torna-se uma palha no rodamoinho.

A história, como o título indica, é contada pelo protagonista do romance, Isaías, a partir de suas lembranças. A motivação seria provar uma tese: a de que os tristes fins dos belos começos das pessoas de origem negra não se deviam à raça, mas a impedimentos sociais. $\mathrm{O}$ argumento parece levar a um livro de análise e crítica social, na forma realista mais ortodoxa, com realce para o tratamento de um tema crucial na sociedade brasileira: o preconceito. Entretanto essa expectativa não se confirma. O texto assume uma dinâmica dissolvente, que pode ser rastreada na constituição de Isaías como indivíduo e nas formas da cidade.

O conflito inicialmente proposto logo se desfibra como eixo da narrativa, pois a vitória do mundo sobre a personagem é rápida, quase sumária. O jovem mulato vem de uma pequena cidade para o Rio de Janeiro a fim de continuar os estudos, mas sem demora descobre que o nível de instrução mais alto não é esperado das pessoas de sua condição. Na verdade, tal desejo é visto como uma pretensão de sua parte. A sociedade, de maneira tácita mas eficaz, destina a ele os empregos subalternos, arranjados pela proteção. A má vontade contra os seus desígnios, sentida por todos os lados, apresenta-se inicialmente como social, externa, porém demonstra

* Universidade Estadual do Ceará 
efeitos igualmente danosos na dimensão psicológica que assume, enfraquecendoe paralisando Isaías.

A representação do conflito é precisa e complexa, apenas fica a impressão, diante da expectativa criada no início, de que a liquidação social e psicológica de Isaías acontece rápido demais. Sentimos falta de que o jovem estudante insistisse nos seus objetivos, superasse a imobilidade dos primeiros choques, investindo em novas tentativas, o que faria a narrativa ganhar em tensão e entrar de novo no seu eixo. Isso não acontece. Falta aqui uma espécie de individualismo mais robusto e de auto-consciência mais arraigada que garantisse à personagem um atrito extenso e profundo com as estruturas sociais dominantes.

Características psicológicas - uma personalidade fraca, por exemplo - não podem ser isoladas na narrativa como explicação da fraqueza da personagem, pois elementos de natureza variada estão presentes e interferem na formação da individualidade, constituindo também uma base de referência para a ação.

Isaías nos apresenta a família como duas possibilidades antagônicas na vida: a do pai, homem culto, eloqüente, brilhante, e a da mãe, doméstica, ignorante, obscura, minguada. Além da distância cultural entre os dois havia outro complicador: ele era padre. O encontro que havia gerado Isaías tinha sido de momento, sem vida comum do casal. No meio da situação clandestina, o menino se deslumbrava com a ilustração paterna, principalmente em contraste com a obscuridade da mãe.

Portanto, Isaías queria ser como o pai, um modelo que serviria para dar forma ao seu desejo, mas não resistência, tendo em vista a ambigüidade da situação. O padre obviamente não o assumira como filho. Além disso, o estudante talentoso perceberia logo que não era visto pelo lado prestigioso e distinto da família, mas pelo lado fraco; era visto como a mãe, pobre e negra.

Outro incentivo importante para continuar os estudos, além do brilho da figura paterna, vinha de uma professora e do livro que esta lhe presenteara, com o título sugestivo de $O$ poder da vontade. Com isso, Isaías tinha, para se lançar nas agruras da conquista de seu lugar social, um modelo (não apenas de instrução mas de distinção, impregnado da ambigüidade e antagonismo social vividos no ambiente doméstico) e uma convicção individualista (haurida de manual).

As duas bases do desejo e individualismo de Isaías, como se vê, são frágeis e contraditórias em si mesmas. Não existe aqui uma base histórico-cultural que dê apoio e nervo à dignidade de sua posição de indivíduo. Inicialmente confiante e orgulhoso, Isaías se desmonta diante do preconceito e da falta de proteção. Não há um complexo cultural que o ajude a se manter inteiro no seu desejo e lutar, pelo contrário. As lições individualistas d' OPoder da vontade não correspondem a algum tipo de experiência brasileira. A posição individual é reduzida sem maiores dificuldades. 
Para esclarecer melhor o que se entende aqui por um complexo cultural como base da personagem, em sua feição individual, tomemos o romance Angústia, de Graciliano Ramos. Este é um bom exemplo na literatura brasileira. Como Isaías, Luís da Silva, o narrador-protagonista, vem do interior e se emprega como jornalista na capital, depois de passar ali miséria e humilhações. A adaptação de Luís, entretanto, mostra-se muito mais conflituosa. Apagado na cidade, instrumentalizado no jornal, humilhado como homem pelo burguês Julião Tavares, que lhe toma a noiva, o protagonista de Angústia resiste sobre um complexo cultural do passado. As figuras do coronel e do cangaceiro, que estão de maneira complexa e problemática na sua formação, dão para ele uma forma de reagir. Luís não recorre a uma atitude aristocrática ou racional-liberal, no modelo do indivíduo livre e auto-consciente, ou socialis ta, na figura do intelectual revolucionário (que está disponível no romance), para se opor à figura untuosa de Julião Tavares. O contraponto deste para Luís da Silva será o antigo patriarca, autoritário e violento, e o cangaceiro, bandido admirado e sanguinário do sertão. A reação culmina, sendo esses os modelos, com o assassinato do rival, quando o conflito individual se abre em movimentos de contradição e revelação dos mais significativos na literatura brasileira.

De qualquer forma, o complexo cultural que fornece as figuras do tirano ou do bárbaro como modelos de orgulho e integridade individual, é uma base onde o indivíduo pode resistir mais. Os códigos de honra do mundo patriarcal travam por um momento a absorção sem restos do indivíduo desintegrado na cidade, prolongando o conflito e aumentando a tensão no romance. Não se postula aqui uma legitimação da reação de Luís, que é problematizada no romance, e não constituirá solução para nada. Importante é entender como essa forma regressiva serviu de apoio, momentâneo e problemático, aos desejos de integridade individual e consideração social do protagonista.

Com isso, pode-se avaliar melhor o que falta a Isaías. A imagem dúbia do pai - que ao mesmo tempo ama e não assume a paternidade; é ilustrado, culto, brilhante, mas aceita, até com certo benefício, a posição minguada e obscura da mãe - não é um modelo de integridade. A dignidade do indivíduo e da ilustração, aprendida teoricamente na família e na escola, constitui valores que a lógica social dominante não apenas desmente mas já absorveu.

A dignidade do saber de Isaías está ligada a um desejo de distinção. A valorização do estudo em um país de analfabetos, com estrutura econômico-social excludente e forma de ação particularista, traduz-se muito mais em distinção do ilustrado do que em motivo de expansão e democratização do conhecimento, abrindo espaço maior para os pobres. A dignidade do saber, portanto, não é por si mesma contrária à lógica dominante, mas já sofreu um tipo de perversão necessário à sua 
coexistência com o sistema excludente, trocando pelo fetiche a parte que seria propriamente social, democrática ou universalizante e poderia incluir a figura da mãe. Além disso, o conhecimento não é a verdadeira chave para a distinção; a chave são os imponderáveis dos caprichos de protetores.

Em resumo, Isaías não tinha um exemplo de alguma maneira heróico ou inteiriço para se espelhar; o amor pelos estudos, ligado à distinção e à mercê do protetor, também não recomendava o confronto. Na fraqueza de Isaías, portanto, está a falta de uma bagagem cultural, ou de algum tipo de tradição arraigada, diferente da dominante, que desse feições mais definidas e irredutíveis ao indivíduo.

Com a derrota de Isaías, a narrativa pode seguir o seu curso dissolvente. É verdade que os desmandos são fortemente satirizados, mas eles reinam quase sem contraste. O mundo e os homens são assim. O narrador satírico - Isaías recordando - constitui até certo ponto um contraste, pois o tempo decorrido distancia e aprofunda a experiência, mas não o suficiente para deter a dissolvência em curso, que reverte sobre a atuação do narrador.

Exemplo dessa reversão é o episódio do suicídio de Floc, introduzido pelo narrador com uma frase empertigada, cheia de uma dignidade estranha ao ambiente do romance. $\mathrm{O}$ tal suicídio é apresentado pelo narrador como prova de uma crença ainda existente no "Sério", no "Verdadeiro" e na "Perfeição", com as iniciais maiúsculas. Essa atitude e o juízo questionável acerca do desespero de Floc são demonstrações de que o narrador tentou deter o curso dissolvente, tomando por conflito essencial algo de outra ordem, mais compreensível no romance que Lima Barreto publicaria a seguir. A situação de Floc é muito parecida com a de Ismênia, a moça que enlouquece por não casar, no Triste fim de Policarpo Quaresma .A ruína de ambos resulta de levarem a sério demais a situação alienada e não de um conflito essencial entre o mundo e o indivíduo impregnado dos grandes valores.

Representar o indivíduo sem grandeza de convicções e ações foi um desafio que o romance brasileiro quase sempre teve de enfrentar. A dificuldade de representação aparece em romances brasileiros anteriores, por exemplo em Macedo e Alencar, resolvida pela atribuição de uma base cultural que é européia; ${ }^{1}$ no caso de Machado, a dissolvência é enformada pelo capricho do narrador, onde se situa o ponto de vista dominante. Sem a base européia e o capricho de classe dominante,

1 A base cultural européia, entretanto, causa descompasso entre as personagens, suas idéias e ações, nos romances desses autores, como nos mostra Roberto Schwarz, no livro Ao vencedor as batatas (1988). Ora as personagens são muito acanhadas para ter certos rompantes de dignidade e convicção, como em Macedo. Ora são censuradas "por seu pouco relevo moral”, como Seixas, personagem do romance Senhora, de José de Alencar (p. 35-79). 
resta nos livros de Lima Barreto a existência de um indivíduo comum, com idéias e convicções sem base nos processos sociais e sem força para gerar conflitos capazes de dar o travejamento esperado à narrativa.

A Vanguarda européia, no início do século XX, formou-se contra esse tipo de dificuldade, que já conhecíamos de longo tempo. A expansão capitalista da virada do século XIX para o XX mudou o aspecto das cidades, impôs uma organização maior da vida e do trabalho, proporcionou um teste e uma crise aos valores da sociedade européia. As inovações científicas e tecnológicas abalaram mentalidades arraigadas e antigas formas de percepção do mundo. O progresso nesses moldes fez uma trajetória destrutiva, que desestabilizou também as bases de um individualismo forte, a convicção sobre a dignidade e o valor do indivíduo. Este resultava de tudo muito diminuído. A industrialização e a padronização dos trabalhos no sistema capitalista - o taylorismo era considerado uma invenção demoníaca por um autor como Kafka -, formam o contexto principal das dificuldades de representação enfrentadas pelos escritores de Vanguarda, na Teoria estética de Adorno.

No debate sobre o expressionismo, Lukács condena a narrativa de Vanguarda pela representação maciça dos indivíduos pobres, das subjetividades alienadas. Estes conduziam, na visão do crítico húngaro, a uma narrativa sem desdobramentos e sem saída, eram caricaturas de caricaturas, um retrato unilateral, angustiado e conformista da sociedade liberal burguesa em crise. ${ }^{2}$ Para Brecht, se o sistema capitalista produzia indivíduos atrofiados, era natural que os escritores quisessem representá-los e obviamente não podiam enriquecê-los artificialmente. ${ }^{3}$ O objetivo aqui não é entrar nesse debate, mas mostrar como a representação da subjetividade pobre, colocada no centro e mesmo como foco da narrativa, exigia redefinições do romance.

Estudamos até aqui a fraqueza de Isaías como precariedade do ponto de vista de um apoio cultural e ideológico à sua posição de indivíduo. Mas a dificuldade de resistir e se contrapor também está ligada à forma de ação do mundo sobre ele. No livro de Lima Barreto, o controle e apagamento do indivíduo aparecem muito mais difusos do que em Angústia. Luís da Silva terá ao menos a figura concreta de

2 LUKÁCS, Georg. Realismo Crítico hoje. Brasília: Coordenada, 1969.

3 BRECHT, Bertolt. Observações sobre um ensaio. In: MACHADO, C. E. J. Um capitulo da história da modernidade estética: debate sobre o expressionismo. São Paulo: Unesp, 1998. O texto de Brecht foi traduzido e incluído por Carlos Eduardo Jordão Machado em apêndice do livro acima referenciado, que apresenta de maneira detalhada e criteriosa o debate sobre a Vanguarda européia, incluindo além destes a posição de Walter Benjamin, Theodor Adorno, Ernst Bloch, entre outros intelectuais e artistas. 
Julião Tavares, como encarnação de tudo o que odeia e rejeita na cidade, os valores e forma de vida burgueses. O deputado Castro, que desampara Isaías, é uma figura de difícil acesso e não nega apoio diretamente, apenas desconversa, manda esperar. $O$ padeiro que o rejeita para trabalhar de entregador faz apenas o que qualquer um faria. O espanto diante da sua intenção de estudar é de várias pessoas. Nenhuma das figuras se individualiza como antagonista de Isaías, constituindo todas elas antes o mecanismo social. No decorrer da narrativa, o protagonista mesmo vai perdendo a individuação.

O controle sobre o destino de Isaías é forte, mas difuso. As responsabilidades estão mediadas pelo sistema, impedindo uma aversão direta, pessoa a pessoa. Formas de luta importantes contra o sistema, a partir de sua situação, não existem. A convicção revolucionária entre os rapazes de suas relações é um palavreado que mal esconde o particularismo. Então Isaías desiste também porque não há como lutar contra o sistema, que ele chama logo no começo de cipoal.

Exceto Clara dos Anjos, em que o jovem Cassi, branco e de boa família, encarna todas as qualidades repugnantes - maldades inatas e sociais -, os romances de Lima Barreto não possuem normalmente antagonistas. Os fracassos de seus personagens são devidos em parte a eles mesmos, em parte ao sistema social, apresentado de maneira impessoal. As conhecidas caricaturas de Lima Barreto têm, entre outras atribuições em seus textos, a de ressaltar as funções e a idéia de sistema, impedindo que os conflitos se acirrem de maneira interpessoal: entre Isaías e Castro ou Loberant, entre Policarpo e Floriano, por exemplo. O caráter difuso dos relacionamentos significa uma dificuldade a mais de contraposição para seus protagonistas, porém essa estrutura os beneficia com uma visão desde sempre lúcida, que não supervaloriza obstáculos pontuais ou pessoais.

O sistema social é mostrado como um mecanismo de controle. Isaías descobre, na má vontade do deputado Castro, que a proteção não é apenas uma ajuda, um laço na cidade desintegrada, uma ponte para entrar no sistema. A proteção controla, define o destino, como já sabiam antes dele Estela e Luís Garcia, do romance Iaiá Garcia, de Machado de Assis. A novidade no romance de Lima Barreto é que esse controle, regulando a vida social, atua dentro de um certo consenso. Neste caso, o do preconceito. A representação foca num aspecto em que o problema se encontra mais generalizado: a expectativa sobre o destino das pessoas negras. A participação social na expectativa rebaixada é quase total e inclui responsabilidades em graus diferentes. O deputado doutor Castro tem uma culpa mais direta, assim como o padeiro que lhe nega o emprego, mas o simples espanto com sua intenção de estudar já indica, atualiza e reforça o padrão social arraigado de preconceito. A partir de certo ponto, o próprio Isaías rebaixa suas expectativas. Nessa camada mais 
difusa, menos palpável e mais inelutável é que Lima Barreto apresenta o preconceito contra o jovem estudante.

O cipoal de Isaías, portanto, revela o sistema social excludente, que marginaliza o pobre, o negro, a mulher, e onde o capricho de classe dominante funciona como uma espécie de loteria. O controle dos romances de Lima Barreto, portanto, não é a padronização da vida, do tipo que existia na Europa industrializada, embora também tenha a ver com papéis e funções sociais. O Rio de Janeiro, e nenhum outro lugar do Brasil, era industrializado na primeira década do século $\mathrm{XX}$, quando esse romance foi escrito. Mas nossa ligação com o sistema capitalista europeu não nos deixou isentos dos problemas trazidos por seus avanços. No Brasil, a expansão serviu para destruir os últimos entraves para a justificação social do enriquecimento sem produção, da especulação, da atividade dos financistas, dos homens e empresas que ganhavam dinheiro porque sabiam manipular o sistema produtivo e monetário. Foi uma vitória interna do dinheiro, das formas mais avulsas e errantes da mercadoria, que estabeleceram relacionamento com formas arcaicas de sociabilidade brasileiras (o clientelismo, o favor). Esse mesmo momento assistiu ao crescimento significativo das massas urbanas e, dentro destas, o surgimento de uma classe média com ímpeto reinvidicatório.

Talvez isso explique porque a padronização da vida, como organização rígida e insondável do trabalho e do cotidiano, não tenha ênfase no romance. Na verdade, encontramos ali um tipo de padronização "malandra", quando os jornalistas desenvolvem esquemas facilitadores para a escrita de seus artigos de alta cultura e espiritualidade. Levar a sério essas situações é um engano raro e lastimável, um desvio que leva à loucura, ao desespero, até ao suicídio, como no caso de Floc. Mais marcado, em termos de experiência da cidade, no romance de Lima Barreto, é o caráter avulso de coisas e pessoas.

Osman Lins identificou a atuação de um "ácido desagregador", nos romances de Lima Barreto, impedindo a ligação entre as pessoas. ${ }^{4} \mathrm{O}$ romance de Isaías é o mais radical na inexistência de relações duradouras ou consistentes de qualquer ponto de vista. Não por acaso é o romance do indivíduo jogado na cidade, que não se firma pelo flanco individual, como na determinação alienada de Policarpo, ou da cidade, no ânimo integrador da experiência urbana em Gonzaga de Sá.

As pessoas simplesmente passam pela vida de Isaías e em algum momento desaparecem. Laje da Silva foi o primeiro conhecimento do rapaz no Rio de Janeiro e também o primeiro a se espantar vivamente com sua intenção de estudar. Era um

4 LINS, Osman. Lima Barreto e o espaço romanesco. São Paulo: Ática, 1976. p. 54. 
padeiro de Itaporanga, informação que, parte sim, parte não, combinava com a impressão física e psicológica que o homem causava, na avaliação de Isaías. Essa ambigüidade despertou a desconfiança, alternadamente reforçada e mitigada pelo tratamento lisonjeiro, da quase adulação que lhe dispensava o padeiro, chamandoo sempre de "doutor". Na companhia deste, Isaías chegou a conhecer alguns jornalistas, categoria que o outro prezava bastante. Mais tarde, quando Isaías se viu abandonado do protetor e se tornou apenas um rapazinho pobre na cidade, Laje da Silva passou a desprezá-lo.

Com pouco dinheiro e sem promessa de emprego, depois da entrevista frustrada com doutor Castro, Isaías se mudou para uma casa de cômodos, um cortiço, onde conheceu Abelardo Leiva, poeta e revolucionário. Nesse momento, teve contato com outros rapazes pobres, que abraçavam de maneira mesclada e confusa $o$ socialismo, o anarquismo e o positivismo. A relação de Isaías com Leiva consistia em longos passeios pela cidade, que duravam quase o dia inteiro, separando-se os dois apenas na hora das refeições, quando cada um tratava de se arranjar como pudesse. No mais, sentavam-se em algum café e Isaías assistia às discussões acaloradas, que encontravam "soluções para tudo". Na verdade, o novo amigo tinha certas contradições que faziam duvidar de sua integridade: se o revolucionário queria a derrocada da sociedade burguesa, o poeta amava as mocinhas bem postas de Botafogo, as veleidades da moda e chegava a passar fome para comprar roupas e perfumes. A amizade entre os dois jovens não se aprofundou e se dissolveu de uma maneira muito peculiar ao romance. O narrador lembra de maneira sucinta, levemente amarga, como depois que se empregou de contínuo no jornal, Leiva passou a visitálo bastante ali, a cavar para si mesmo, até arranjar o lugar de repórter policial, quando tratou de se afastar do colega em posição inferior.

Ainda na condição de estudante, Isaías conheceu, por intermédio de Laje da Silva, o estrangeiro Ivã Gregoróvitch Rostóloff, que trabalhava no Brasil como repórter. Isaías também desconfiou dele inicialmente, por causa dos títulos e trabalhos esdrúxulos, os quais se atribuía. A desconfiança, nesse caso, tendeu a ceder, por causa de uma simpatia mútua. Encontravam-se na rua do Ouvidor e conversavam, de maneira eventual mas com alguma freqüência. No dia em que Isaías foi chamado à delegacia sob suspeita de furto no hotel e em seguida recebeu a notícia da doença terminal da mãe, Gregoróvitch o encontrou por acaso, apiedou-se dele e interveio para arranjar-lhe o emprego no jornal. A situação humilde do rapaz, que passou a protegido, promoveu uma mudança na relação entre ambos, assumindo o repórter uma atitude distante, condescendente e paternal para com o outro.

A relação com Loberant, o poderoso dono do jornal, foi provavelmente a mais estável, porém claramente de dependência. Isaías se tornou seu protegido por 
obra do acaso. Indo buscar o chefe numa casa noturna, quando Floc se matou com um tiro na redação, flagrou-o em situação não muito apresentável. Com isso, passou a existir para Loberant, que melhorou sua situação no jornal e tornou-o seu companheiro de farras. A relação entre eles não era mais que isto. Depois de um tempo, Isaías se incomodou com a situação à sombra do outro e conseguiu, por intermédio dele ainda, um emprego de escrivão no interior.

As relações se fazem e desfazem na dinâmica da narrativa, que não as aprofunda ou marca seus conflitos. São ligações circunstanciais, avulsas, indicadoras da associação de uma sociabilidade antiga (as relações de favor) com outra emergente (que tende a dissolver as obrigações entre as partes). O caso do deputado Castro é esclarecedor, porque em situação normal, o protetor teria uma carga de obrigação maior, não despediria Isaías de mãos abanando. Talvez o humilhasse ou o agregasse à sua casa, mas não jogaria fora o rapaz. A dificuldade de encontrar o deputado e a atitude indiferente indicam que outra dinâmica começou a funcionar junto da antiga, possivelmente dando mais opções e desenvoltura ao capricho de classe dominante.

A proteção, portanto, se torna mais avulsa. Antes de arranjar o emprego no jornal, Isaías contava com uma pessoa ou outra, que lhe pagava uma refeição, época em que chegou a se alimentar com o intervalo de quarenta e oito horas. A liberdade franqueada tinha a forma de uma mobilidade aleatória. A proteção avulsa dava portanto algum tipo de desenvoltura também ao dependente, talvez por não incluílo no sistema. A maneira tradicional entretanto parece ser, a essas alturas, mais dificilmente tolerada, a julgar pela maneira como Isaías trata de se afastar de Loberant, quando o apadrinhamento se estabiliza e parece só lhe trazer benefícios.

No período de privações, das refeições bem espaçadas, vemos Isaías movimentando-se pela cidade, sem caminho certo e sem destino. "Dei em passear de bonde, saltando de um para outro, aventurando-me por travessas afastadas, para buscar o veículo em outros bairros". ${ }^{5}$ Os passeios, inicialmente solitários, depois em companhia de Leiva, enchem os dias sem afazeres ou compromissos de qualquer espécie, sem estudo ou trabalho. "Saíamos às dez horas, tomávamos café e andávamos até às três ou quatro da tarde". ${ }^{6}$

O romance Vida e morte de M. J. Gonzaga de Sá, do mesmo autor, também nos apresenta dois grandes passeadores: o próprio Gonzaga e seu biógrafo, o jovem amigo Augusto Machado. Embora este romance tenha sido publicado apenas em 1919, temos indicações no diário de Lima Barreto de que os dois livros em foco

5 BARRETO, Afonso Henriques de Lima. Recordações do escrivão Isaías Caminha. São Paulo: Ática, 1984. p. 63.

6 Ibid., p. 64. 
teriam sido escritos quase concomitantemente. Em carta a um amigo, o autor comenta que escolheu estrear com as Recordações... por ser aquele um tanto cerebral e introspectivo demais. ${ }^{7}$ É interessante notar como romances escritos quase ao mesmo tempo vão sentir e revelar de forma tão distinta a mesma cidade. Augusto Machado e Gonzaga descrevem, nos seus passeios, um movimento integrador. A memória do velho amanuense, descendente de um tronco familiar de quatrocentos anos, reanima a história da cidade, revela as ligações e transformações entre passado e presente, propiciando ao jovem Machado uma auto-consciência integrada no meio urbano e crítica em relação às suas mazelas. No mesmo Rio de Janeiro, Isaías surge como um menino vindo do interior, um estrangeiro que teme a grande cidade e reage com desconfiança aos contatos sociais, tendo como únicos aliados um pouco de dinheiro e um bilhete de recomendação. Os dois jovens, ambos mulatos conscientes do preconceito, fazem entretanto roteiros imaginários muito diferentes, andam por cidades aparentemente distantes. $\mathrm{O}$ fato de Lima Barreto ter dado conseqüência a tal diversidade mostra a objetividade com que escrevia suas histórias e levava a sério as situações criadas, além da preocupação com as formas da consciência, que obcecou sua época.

A integração no livro de Gonzaga encontra-se estreitamente ligada a formas antigas, às possibilidades da memória e da experiência. No romance, Augusto Machado ganha-a como prêmio, ou melhor, como herança, marcando um rico momento de transição, que estudamos em trabalho anterior. ${ }^{8}$ Nas Recordações..., nada disso está mais presente. O elo de Isaías com o sistema (não com a cidade e sua história) é a proteção, que falha e depois se reativa por outros meios. Fora disso, o jovem mulato é, ainda mais que outros, um molusco sem concha, árvore sem raiz, uma palha no rodamoinho, para usar as diversas imagens do romance.

A amizade que Isaías adquire pelas notas de dinheiro, em certo momento de desamparo, marca o momento de encontro da trajetória desgarrada do protagonista com a mais avulsa das formas. "Sentia-me só, só naquele grande e imenso formigueiro humano, só, sem parentes, sem amigos, sem conhecidos que a desgraça pudesse fazer amigos. Os meus únicos amigos eram aquelas notas sujas encardidas; eram elas o meu único apoio."

7 BARRETO, Afonso Henriques de Lima. Correspondência. São Paulo: Brasiliense, 1956, v.1. p. 169. A carta é de 1909, ano de publicação das Recordações..., e o destinatário era o também escritor Gonzaga Duque.

8 Minha tese de doutorado estuda o romance Vida e morte de M. J. Gonzaga de Sá como uma narrativa de transições, na esfera da vida e da estética, mostrando nessa estrutura a busca de redefinições própria do início do século XX.

9 BARRETO, op. cit., p. 39. 
No desejo de reter esse único amigo do homem sozinho na cidade, Isaías diz ter entendido muito bem a avareza. Mesmo assim, era necessário deixar as notas aqui e ali. Há um movimento semelhante no romance, que gostaria de reter alguma riqueza, mas é obrigado a vê-la dispersar-se nas relações pobres, circunstanciais, nas expectativas perdidas, nas noções gerais desbaratadas facilmente no contato com a realidade, na própria errância de Isaías que vem de sua cidadezinha para 0 Rio, depois para o interior e, até onde se sabe, volta para o Rio e entra na política. $\mathrm{O}$ curso dissolvente que pode rapidamente transformar tudo, não apenas Isaías, em palha no rodamoinho é a principal perplexidade desse livro de Lima Barreto (maior até que a do preconceito), na visão do presente artigo.

Embora o autor brasileiro se preocupasse com a atualização estética em relação à Europa, como demonstram alguns de seus escritos sobre literatura, e percebesse a época de redefinições que era a sua, não se preocupou, ao que parece, em se apropriar da problemática da Vanguarda. Não gostava de Marinetti e do futurismo, a representante das vanguardas européias mais presente no meio literário brasileiro. Consta que se preocupou com a crise mais geral da mentalidade intelectual européia, o abalo de fundamentos das ciências e das artes, onde radicava também os problemas estéticos e literários desse início de século. Boa parte das redefinições de estilo que o romance de Lima propõe está ligada a questões do próprio sistema literário brasileiro, em relação à linguagem, por exemplo. Na falta de apropriações ou sugestões externas, as redefinições estruturais da narrativa podem ser perseguidas até uma sensibilidade profunda das estruturas sociais brasileiras na época, que o escritor procurou representar.

As formas desagregadoras e problemáticas da cidade como lugar privilegiado da mercadoria encontravam-se aqui com um país desconjuntado, sem consistência social, no sentido rigoroso do termo, devido à grande massa excluída do regime de propriedade e cidadania. A confluência das duas formas dissolventes é percebida e problematizada nos romances de Lima Barreto, resultando sempre em um quê de perplexidade, urgência e melancolia. ${ }^{10}$

A dissolvência da narrativa, entretanto, não significa uma plasticidade perigosa de vale-tudo, não se reduz a uma visão cética, pessimista e toda subjetiva da vida. Os fatos de Isaías não dirigir o seu destino, de a dissolvência refluir sobre o narrador explicando também o seu gesto, constituem um princípio, um limite objetivo dentro da narrativa, que pode ser identificado como a impossibilidade de

10 Nesse sentido, os romances do autor já cabem e podem ser estudados com vantagem, sob a denominação utilizada por Fernando Gil de "romance da urbanização", definindo aquelas obras que buscaram representar e plasmar esteticamente a experiência do processo de urbanização no Brasil. 
mudar o que quer que seja. Não importa que Isaías curta miséria ou seja agraciado pela sorte com um protetor poderoso, que seja contínuo ou repórter, que fique no Rio ou vá ser escrivão no interior, seus objetivos estão fora de alcance, na medida em que implicam uma contrariedade às estruturas dominantes. $\mathrm{O}$ mundo que desmancha tudo ao redor do indivíduo (e a este mesmo), com sua sólida estrutura dissolvente, impõe a todas as personagens do romance uma experiência de paralisia, de inelutável impotência.

\section{RESUMO}

Este artigo estuda o romance Recordações do escrivão Isaías Caminha, de Lima Barreto, enfocando as relações entre indivíduo e vida urbana como desafios para a representação. Mostra o encontro, no romance, de velhas formas dissolventes da sociedade brasileira com as formas dispersivas da cidade, tentando entender como a narrativa se alterou e pôde constituir-se uma experiência complexa e crítica do processo de urbanização no Brasil.

Palavras-chave: Lima Barreto, romance urbano, literatura e urbanização, crise da representação.

\section{ABSTRACT}

This essay studies the novel Recordações do escrivão Isaías Caminha, of Lima Barreto, focusing the relationships between individual and urban life as challenges to representation. It shows the encounter, in the novel, of old dissolvent forms of Brazilian society with dispersive forms of the city, trying to understand as the narrative altered itself and could constitute a complex and critic experience of the urbanization process in Brazil.

Key-words: Lima Barreto, urban novel, literature and urbanization, crisis of representation. 


\section{REFERÊNCIAS}

BARRETO, Afonso Henriques de Lima. Correspondência. São Paulo: Brasiliense, 1956, v. 1. Recordações do escrivão Isaías Caminha. São Paulo: Ática, 1984.

GIL, Fernando C. O romance da urbanização. Porto Alegre: EDIPUCRS, 1999.

LINS, Osman. Lima Barreto e o espaço romanesco. São Paulo: Ática, 1976.

LUKÁCS, Georg. Realismo crítico hoje. Brasília: Coordenada, 1969.

MACHADO, C. E. J. Um capitulo da história da modernidade estética: debate sobre o expressionismo. São Paulo: Unesp, 1998.

OLIVEIRA, Irenísia Torres de. Uma escrita em chão cediço . Rio de Janeiro, 2003. Tese (Doutorado em Literatura Comparada) - Universidade Federal Fluminense.

SCHWARZ, Roberto. Ao vencedor as batatas. 3. ed. São Paulo: Duas Cidades, 1988. 